\title{
RILEM draft recommendation: TC-242-MDC multi-decade creep and shrinkage of concrete: material model and structural analysis*
}

\section{Model B4 for creep, drying shrinkage and autogenous shrinkage of normal and high-strength concretes with multi-decade applicability}

\author{
RILEM Technical Committee TC-242-MDC (Zdeněk P. Bažant, chair)
}

Received: 5 June 2014/Accepted: 2 December 2014

(C) RILEM 2015

\begin{abstract}
In response to the continuously advancing concrete technology, a new prediction model for creep and shrinkage is presented. This model, named B4, builds on the theoretically justified model B3, which is a RILEM recommendation from 1996. Improvements to the model allow for enhanced multi-decade prediction, distinguish between the drying and autogenous
\end{abstract}

*This recommendation was developed by a working group within RILEM TC-247-MDC consisting of Z. P. Bažant (group leader), M. H. Hubler and R. Wendner.

TC Membership:

Chairman: Zdeněk P. Bažant (Northwestern University, Evanston, IL)

Secretary: Milan Jirásek (Czech Technical University in Prague)

Members: Mija H. Hubler (University of Colorado, Boulder, CO); Roman Wendner (BOKU, Vienna); Matěj Lepš , Vít Šmilauer, Lukáš Vráblík (Czech Technical University in Prague); Ignacio Carol (Universidad Politecnica de Catalunya, Barcelona); Luigi Cedolin (Politecnico di Milano); Gianluca Cusatis (Northwestern University, Evanston, IL); Jialiang Le (University of Minnesota, Minneapolis); Koichi Maekawa (University of Tokyo); Yunping Xi (University of Colorado, Boulder) and Goangseup Zi (Korea University, Seoul) Acknowledgements: Thanks for useful comments are due to non-voting consulting members (RILEM non-members) Alessandro Beghini, Walter Dilger, Petr Havlásek, K.-T. Kim, Vladimír Kř́istek, G. Pijaudier-Cabot, Tada-Aki Tanabe, Franz-Josef Ulm, Matthieu Vandamme, Jan Vítek, Kaspar Willam and Qiang Yu. Finally, the comments by an internal Reviewing Group, consisting of Milan Jirásek (Group leader), Vít Šmilauer and Lukáš Vráblík, were very helpful for the final tuning of the model. shrinkage, and introduce new equations and parameters to capture the effects of various admixtures and aggregate types. The development and justification of the model is described in three companion articles which follow.

\section{Introduction}

Most advances in structural engineering come in response to failures and damages. Concrete creep is no different. The latest stimulus was provided by the fatal 1996 collapse of the KB Bridge in Palau with the span of $241 \mathrm{~m}$, which was the world record for a segmentally erected prestressed box girder. The collapse, triggered by an unsuccessful retrofit, brought attention to an unrelated problem, namely that this bridge suffered grossly excessive creep deflections, which reached $1.61 \mathrm{~m}$ (compared to design camber), and a prestress loss of about $50 \%[1,2]$. Both occurred within 18 years, while most large bridges are nowadays required to be designed for a lifetime of at least 100 years.

This disastrous experience led to the creation of the RILEM Committee TC-MDC (Multi-Decade Creep). A search under the RILEM aegis, supported by a major grant to Northwestern University from the U.S.

RILEM Technical Committee TC-242-MDC

(Zdeněk P. Bažant, chair) ( $₫)$

Northwestern University, Evanston, IL, USA

e-mail: z-bazant@northwestern.edu 
Department of Transportation (DoT), led to a collection of multi-decade deflection data of 69 large-span prestressed bridges from around the world, most of which suffered excessive deflections resulting in bridge closing or costly retrofit [3]. The analysis revealed that all the design codes and standard recommendations led to severe underestimation of multi-decade creep.

A key insight from the analysis of the KB Bridge and other similar ones [1, 2] was that the existing RILEM database, in which $95 \%$ of all creep tests have a duration of less than 6-years and only a few exceed 12 years, is insufficient for calibrating and validating multi-decade prediction models and must, therefore, be combined with inverse inferences from bridge deflections and must, of course, be based on sound theory. A new database, more than twice as large, was developed at Northwestern in collaboration with TC-MDC, under the US Department of Transportation funding. This world-wide database contains 1,400 creep tests and 1,050 shrinkage tests and also includes data on the 69 bridges. Compared to the previous RILEM database [4], the new extension also includes many data on modern high performance concretes with various admixtures [5], and data on autogenous shrinkage which is an important feature of such concretes.

This new database, including the bridge data, made it possible to calibrate the present model B4, which represents a major improvement over model B3 $[6,7]$ and is the fourth in a series of progressively improved models developed at Northwestern University since 1978. Since the general mathematical form of model B3 has been theoretically supported by the solidification theory, theory of microprestress relaxation in the nano-structure, activation energy concepts, moisture diffusion theory and damage models for microcracking [8-11, e.g.], the same mathematical form is retained in model B4, except for the autogenous shrinkage. But the formulas giving the dependence of the creep and shrinkage parameters on the concrete strength, mix composition, cement and aggregate types, and curing procedure have been completely revised and refined, based on extensive statistical optimization of a new extensive database of laboratory tests. The simultaneous optimization of the bridge database provided essential information for updating the asymptotic slope of compliance curves in the semilogarithmic scale. The database expansion made it also possible to include the autogenous shrinkage, which was not separately considered in B3, take into account further influences such as the mineralogical type of aggregate, and extend the applicability to modern concretes. For the calibration, various strategies that help to suppress statistical bias were used.

\subsection{Ranges of applicability and required accuracy}

The degree of sensitivity of various structures to creep and shrinkage varies widely. A sophisticated model such as B4 is necessary only for certain special types of structures. The following approximate classification of sensitivity levels of structures, similar to that specified for model B3, may be made on the basis of general experience [7]:

Level 1. Reinforced concrete beams, frames and slabs with spans under $20 \mathrm{~m}(65 \mathrm{ft})$ and heights of up to $30 \mathrm{~m}$ (100 ft), plain concrete footings, retaining walls.

Level 2. Prestressed beams or slabs of spans up to $20 \mathrm{~m}$ (65 ft), high-rise building frames up to $100 \mathrm{~m}$ (325 ft) high.

Level 3. Medium-span box girder, cable-stayed or arch bridges with spans of up to $80 \mathrm{~m}(260 \mathrm{ft})$, ordinary tanks, silos, pavements, tunnel linings.

Level 4. Long-span prestressed box girders, cablestayed or arch bridges; large bridges built sequentially in stages by joining parts; large gravity, arch or buttress dams; cooling towers; large roof shells; very tall buildings.

Level 5. Record span bridges, nuclear containments and vessels, large offshore structures, large cooling towers, record-span thin roof shells, record-span slender arch bridges, super-tall buildings.

Level 5 requires the most realistic and accurate analysis based on a model such as B4 (or B3) - typically a step-by-step computer analysis based on a rate-type constitutive law and damage constitutive model, coupled with the solution of the differential equations for drying and heat conduction, statistical estimation of confidence limits, and updating based on short-time tests of the given concrete. Designers usually prefer simpler methods of analysis, but it makes little sense to run a detailed finite element analysis with statistical estimates and updates based on short-time tests of given concrete if a simplistic material model is used. The cost of proper Level 5 analysis is minuscule compared to the cost of large structures of extreme designs. The error in maximum deflections, stresses and cracking predictions caused by replacing a realistic analysis with a simple but 
simplistic estimation of creep and shrinkage effects is often larger than the gain from replacing old-fashioned frame analysis by pencil with finite element analysis by computer.

For sensitive structures (Levels 5 and 4), model B4 should be used in rate-type form for analysis in many time steps $[1,2,12]$. For lower level sensitivity, the analysis based on model B4 can be carried out by the age-adjusted effective modulus method [13], endorsed by ACI [14] and fib [15]. This is recommended for levels 3 and lower. This method is nevertheless also useful for preliminary design estimates at levels 4 and 5. The effective modulus method suffices for level 2. For level 1, creep and shrinkage analysis of the structure is not required, although a crude empirically based estimate using the effective modulus is desirable to check whether level 1 is indeed applicable.

The foregoing categorization is, however, gradually loosing its practical usefulness as design firms acquire realistic programs for creep structural analysis. When a firm already has a program based on model B4, then using it for levels 2 or 3 presents no more trouble than using a simpler program based on a simpler creep and shrinkage model. To facilitate it, the B4 program automatically assigns default values of those parameters that are unknown and unspecified, and thus no more input is necessary than for the simpler models.

Since creep and shrinkage deformations inevitably exhibit large statistical scatter, a statistical analysis with an estimation of $95 \%$ confidence limits should be mandatory for level 5, and is recommended for level 4 . The present paper gives some statistical information needed for this purpose. More is provided in a subsequent companion paper. If high temperatures occur, their analysis ought to be detailed for level 5 and approximate for level 4. For level 3, their analysis is unnecessary though advisable, and can be ignored for levels 1 and 2, except for the creep caused by hydration heat in massive structures.

\subsection{Basic notations}

$t$

$t^{\prime}$

$t_{0}$

$\hat{t} \quad$ temperature corrected current age

$\hat{t}^{\prime} \quad$ temperature corrected age at loading $\tilde{t}_{0}$ $J\left(\hat{t}, \hat{t}^{\prime}\right)$ or $J\left(t, t^{\prime}\right)$ $C_{0}\left(\hat{t}, \hat{t}^{\prime}\right)$ $C_{d}\left(\hat{t}, \hat{t}, \tilde{t}_{0}\right)$ $\epsilon_{s h}\left(\tilde{t}, \tilde{t}_{0}\right)$ $\epsilon_{s h \infty}\left(\tilde{t}_{0}\right)$ $h$

$T$

$T_{\text {cur }}$

$U_{h}, U_{s}, U_{c}$

$R$

$H$

$S(\tilde{t})$

$\tau_{s h}$

$V / S$

$D$

$c$

$w / c$

$a / c$

$\underline{f_{c}^{\prime}}$

$E_{28}$

$\rho$ temperature corrected exposure duration temperature corrected age at exposure total compliance (strain at time $\hat{t}$ or $t$ caused by a unit uniaxial sustained stress applied at age $\hat{t}^{\prime}$ ) or $t^{\prime}$ basic creep compliance (i.e., compliance at no moisture exchange) additional compliance due to drying creep shrinkage strain ultimate shrinkage strain $(\tilde{t} \rightarrow \infty)$ relative humidity of the environment, expressed as a decimal temperature of the environment temperature of the environment during curing activation energies for hydration (subscript h), drying shrinkage (s), and creep (c) gas constant average of the pore relative humidity over the cross-section function defining the shape of shrinkage curve shrinkage halftime in days volume-surface ratio ( $\mathrm{mm}$ ) effective cross-section thickness as computed from V/S cement content (mass per $1 \mathrm{~m}^{3} \mathrm{of}$ concrete)

water-cement ratio in the mix (by weight) aggregate-cement ratio in the mix (by weight) required design strength mean cylinder strength at 28 days mean Young's modulus at 28-days mass density of concrete in $\mathrm{kg} / \mathrm{m}^{3}$
Although the range of applicability might be broader, the ranges of various parameters for which model B4 has been calibrated are typical for practice and are as follows:

$$
\begin{aligned}
& 0.22 \leq w / c \leq 0.87, \quad 1.0 \leq a / c \leq 13.2 \\
& 2,070 \mathrm{psi} \leq \bar{f}_{c} \leq 10,000 \mathrm{psi}, 12.5 \mathrm{lb} / \mathrm{ft}^{3} \leq c \\
& \quad \leq 93.6 \mathrm{lb} / \mathrm{ft}^{3} \text { inch-pound system }
\end{aligned}
$$




$$
\begin{aligned}
& 15 \mathrm{MPa} \leq \bar{f}_{c} \leq 70 \mathrm{MPa}, 200 \mathrm{~kg} / \mathrm{m}^{3} \leq c \\
& \quad \leq 1,500 \mathrm{~kg} / \mathrm{m}^{3} \text { SI system } \\
& -25^{\circ} \mathrm{C} \leq T \leq 75^{\circ} \mathrm{C} \\
& 20{ }^{\circ} \mathrm{C} \leq T_{\text {cur }} \leq 30^{\circ} \mathrm{C} \\
& 12 \leq V / S \leq 120
\end{aligned}
$$

The above range of applicability is broader than that of Model B3. This has been made possible by calibration with multi-decade bridge data, and with a broader range of compositions and concrete strengths; see [5].

Note that all the creep tests used for calibration were conducted under centric uniaxial compression. Therefore the present model does not apply to bending or highly eccentric load, because the microcracking and interaction of stress distribution with pore humidity are different. However this is not a problem for deep beams, e.g., bridge box girders, when the walls are subdivided into through-thickness finite elements in which the variation of compressive stress over the element is always minor.

Because bridge deflection data were part of the calibration, the B4 formulas should apply to multidecade durations. They also apply to durations as short as $1 \mathrm{~s}$ (or even shorter), but they are neither intended nor calibrated for concretes younger than 1 day or sections smaller than 2 in. (51 mm). In particular, the model is not intended for predicting the early-age (i.e., early-hour) shrinkage development, which is mainly governed by exothermal chemical reactions and the transition between liquid and solid phases.

The creep curves are rather smooth, lacking any characteristic time, and model B4 describes them realistically even for very short times. These facts are important for extrapolating short-time creep tests of 1-3 months durations to multi-decade durations. However, the same is not true of drying shrinkage and the drying part of creep because the characteristic time, represented by the drying halftime, cannot be determined from drying exposures of a few months duration. For that purpose, it is helpful to measure the moisture loss (or weight loss) of the shrinkage specimens or their identical companions and compare it to an estimate of the final water loss. Although the methodology of doing that has been formulated and experimentally verified nearly two decades ago (see Eqs. 1.30-1.34 and Fig. 1.4 in [7]), it is deplorable that nearly all the shrinkage tests, even the recent ones, skip the weight loss measurement $[16,17]$. It must be emphasized that any short-time shrinkage and drying creep tests of a concrete to be used in a sensitive structure of level 4 or 5 should be accompanied by weight loss measurements from which the halftime can be approximately identified, as proposed in [7].

The creep coefficient, $\phi\left(t, t^{\prime}\right)$, which is convenient for simplified analysis of creep effects in structures, is defined as:

$$
\phi\left(t, t^{\prime}\right)=E\left(t^{\prime}\right) J\left(t, t^{\prime}\right)-1
$$

and should always be calculated from this equation; $E\left(t^{\prime}\right)=$ (static) modulus of elasticity at loading age $t^{\prime}$ as calculated from compliance $J\left(t, t^{\prime}\right)$ for short duration $\Delta=t-t^{\prime}$, typically $\Delta=0.001$ day $\approx 1.5 \mathrm{~min}$. Note that, for structural calculations, only the values of $J\left(t, t^{\prime}\right)$ are important and various combinations of $\phi$ and $E$ corresponding to any chosen $\Delta$-value between $0.1 \mathrm{~s}$ to $2 \mathrm{~h}$ yield about the same structural creep effects for long times. Large errors can occur when an incompatible $E$ value, e.g. that obtained from the code formula or a standardized $E$-modulus test, is used.

\subsection{Equivalent times at different temperatures}

The equivalent times for creep $\hat{t}, \hat{t}$, and shrinkage $\tilde{t}$, and $\tilde{t}_{0}$ are introduced to allow the model to capture the temperature effects on the creep and shrinkage rates, and the aging rates. For theoretical reasons, all these effects should be time accelerations or decelerations governed by activation energies $U$, resulting in a horizontal shift of the curves in the logarithmic scale. The temperature effect on the curing and aging process may be described as:

$\tilde{t}_{0}=t_{0} \beta_{T h}, \quad \beta_{T h}=\exp \left[\frac{U_{h}}{R}\left(\frac{1}{293}-\frac{1}{T_{\text {cur }}+273}\right)\right]$

for any constant temperature $T_{\text {cur }} \in\left[20^{\circ} \mathrm{C}, 30^{\circ} \mathrm{C}\right]$

$T_{c u r}=$ temperature at curing (all the temperatures are here given in ${ }^{\circ} \mathrm{C}$ ); $U_{h}=$ activation energy of hydration. Similarly, the duration of drying $t-t_{0}$ and the sustained stress duration $t-t^{\prime}$ are accelerated as: 
$\tilde{t}=\left(t-t_{0}\right) \beta_{T s}, \quad \beta_{T s}=\exp \left[\frac{U_{s}}{R}\left(\frac{1}{293}-\frac{1}{T+273}\right)\right]$

$\hat{t}^{\prime}=t_{0} \beta_{T h}+\left(t^{\prime}-t_{0}\right) \beta_{T s} \quad$ and $\quad \hat{t}=\hat{t}^{\prime}+\left(t-t^{\prime}\right) \beta_{T c}$,

$\beta_{T c}=\exp \left[\frac{U_{c}}{R}\left(\frac{1}{293}-\frac{1}{T+273}\right)\right]$

where $U_{s}$ and $U_{c}$ are the activation energies of moisture diffusion and of creep. In absence of data for the given concrete, one can use $U_{h} / R=U_{s} / R=$ $U_{c} / R=4,000 \mathrm{~K}$. Note, temperature $T$ in $\beta_{T s}$ and $\beta_{T c}$ corresponds to the average environmental temperature before and after load application respectively. When the temperature is $20^{\circ} \mathrm{C}$, the equivalent times reduce to actual times and durations, i.e.,

$\tilde{t}_{0}=t_{0}, \quad \tilde{t}=t-t_{0} \quad$ and $\quad \hat{t}^{\prime}=t^{\prime}, \quad \hat{t}=t$

Within the service stress range (i.e., up to about $0.45 \bar{f}_{c}$, where $\bar{f}_{c}=$ mean cylinder strength at age 28 days), all the apparent nonlinearity of creep of structures is due to cracking which can be captured separately (e.g., by finite element programs). Thus, the creep may be considered to depend linearly on stress and follow the principle of superposition. A stress $\sigma$ that is applied at age $t^{\prime}$ and remains constant thereafter causes a strain $\epsilon(t)$ at age $t$ which is defined by

$\epsilon(t)=J\left(\hat{t}, \hat{t}^{\prime}\right) \sigma+\epsilon_{\text {sh,total }}\left(\tilde{t}, \tilde{t}_{0}\right)+\alpha_{T} \Delta T$

in which $J\left(\hat{t}, \hat{t}^{\prime}\right)$ is the compliance function = strain (creep plus elastic) at the current time $t$ caused by unit uniaxial constant stress $\sigma$ applied at age $t^{\prime}, \epsilon=$ strain (both $\sigma$ and $\epsilon$ are positive in tension); $\epsilon_{\text {sh,total }}=$ total shrinkage strain (negative for a decrease in volume); $\Delta T(t)=$ temperature difference from the reference temperature at time $t$, and $\alpha_{T}=$ thermal coefficient of expansion. The flow chart in Fig. 1 provides an overview of the necessary steps and their interactions, and it also indicates the main equations and tables of Model B4.

\subsection{Average shrinkage of a cross-section}

The relative humidity in the pores of concrete is initially $100 \%$. Exposure to the environment engenders a long-term drying process (described by the solution of the diffusion equation), which causes drying shrinkage and additional creep during drying.

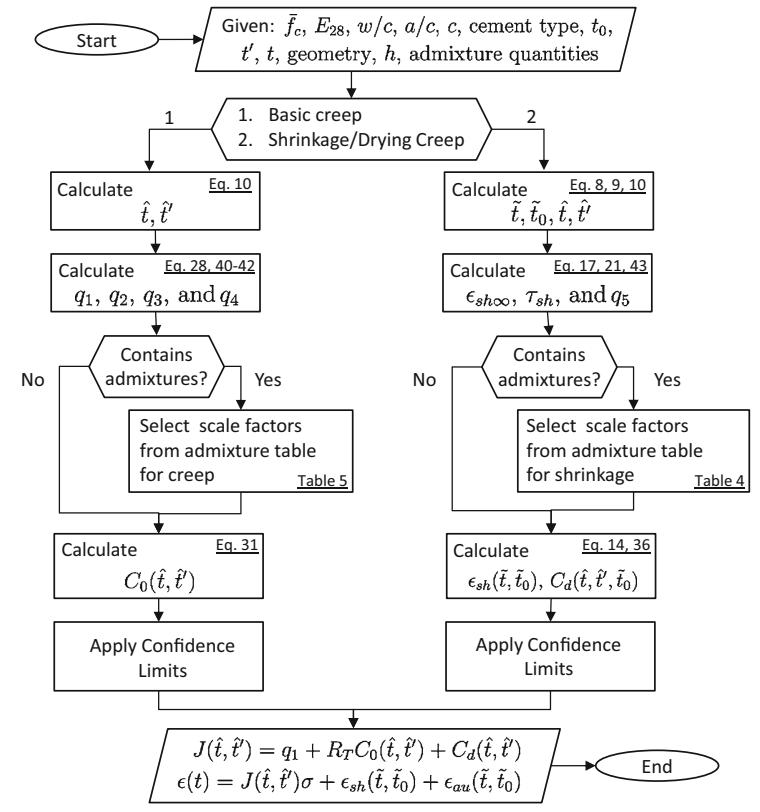

Fig. 1 Flow chart showing the calculation procedure for the B4 model

In the absence of moisture exchange (as in sealed concrete), a gradual decrease of pore humidity, called self-desiccation, is nonetheless observed. Normalstrength concretes with high $w / c$ (water-cement ratio) self-desiccate to about 97-99\% percent, but modern high performance concrete with admixtures and low $w / c$ can self-desiccate to $85 \%$ or even $80 \%$. The socalled autogenous shrinkage, which is the result of chemical reactions causing self-desiccation, occurs already during the curing of concrete. All the points in a cross section exhibit nearly the same autogenous shrinkage until a drying front, which propagates rather slowly, interferes.

In normal concretes of high $w / c$, the autogenous shrinkage is usually very small and has historically been neglected. However, high-strength concretes, which use low $w / c$, and modern cements containing reactive fillers and admixtures exhibit significant autogenous shrinkage. Therefore, model B4 splits shrinkage into an autogenous part, $\epsilon_{a u}$, and a drying part, $\epsilon_{s h}$. Based on optimizing the fit of the shrinkage database, $\epsilon_{a u}$ and $\epsilon_{s h}$ are assumed to be approximately non-interactive and additive:

$\epsilon_{\text {sh }, \text { total }}\left(\tilde{t}, \tilde{t}_{0}\right)=\epsilon_{s h}\left(\tilde{t}, \tilde{t}_{0}\right)+\epsilon_{a u}\left(\tilde{t}, \tilde{t}_{0}\right)$

While autogenous shrinkage begins at the time of setting $t=0$, drying shrinkage begins only after 

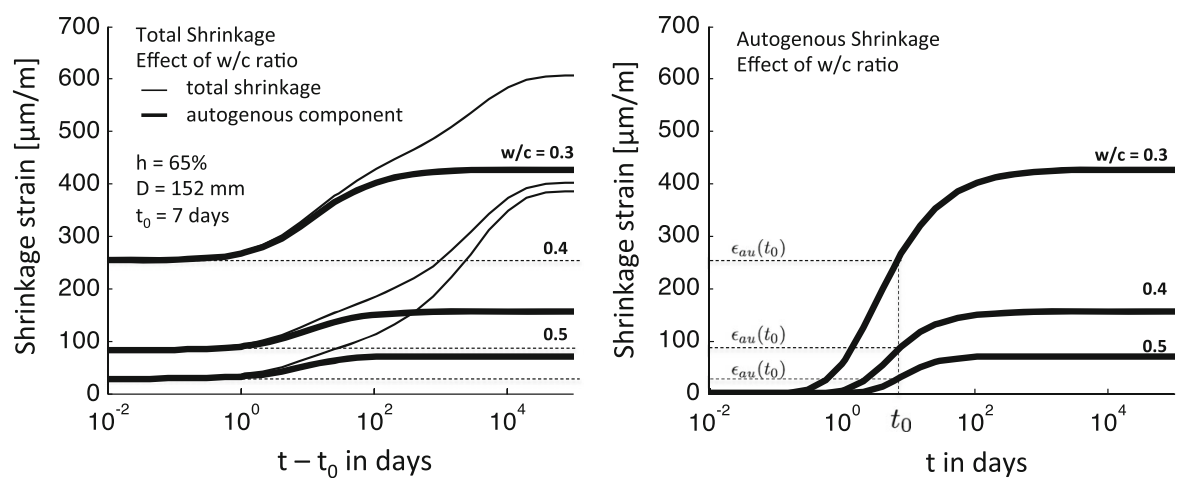

Fig. 2 Typical curves illustrating the contribution of autogenous shrinkage to total shrinkage using the B4 model

exposure to the environment at time $t_{0}$. Fig. 2 illustrates the predicted amount of autogenous shrinkage (bold line) and total shrinkage (solid line) as a function of the relative time after exposure to the environment $t-t_{0}$ in dependence of the water-cement-ratio $w / c$. The vertical offset in the left plot corresponds to $\epsilon_{a u}\left(t_{0}, t_{0}\right)$, as illustrated on the right side.

\section{Drying shrinkage:}

$\epsilon_{s h}\left(\tilde{t}, \tilde{t}_{0}\right)=\epsilon_{s h \infty}\left(\tilde{t}_{0}\right) k_{h} S(\tilde{t})$

Time curve:

$$
S(\tilde{t})=\tanh \sqrt{\frac{\tilde{t}}{\tau_{s h}}}
$$

Final drying shrinkage:

$$
\begin{aligned}
& \epsilon_{0}=\epsilon_{c e m}\left(\frac{a / c}{6}\right)^{p_{\epsilon a}}\left(\frac{w / c}{0.38}\right)^{p_{\epsilon w}}\left(\frac{6.5 c}{\rho}\right)^{p_{c c}}, \\
& \rho=2,350 \mathrm{~kg} / \mathrm{m}^{3}
\end{aligned}
$$

Shrinkage correction for the effect of aging on elastic stiffness (co-opted from model B3 [6]):

$$
\epsilon_{s h \infty}\left(\tilde{t}_{0}\right)=-\epsilon_{0} k_{\epsilon a} \frac{E\left(7 \beta_{T h}+600 \beta_{T s}\right)}{E\left(\tilde{t}_{0}+\tau_{s h} \beta_{T s}\right)}
$$

The type of aggregate is taken into account by the dimensionless factor $k_{\epsilon a}$ according to Table 6, which can be set to 1 if no information on aggregate type exists. The shrinkage halftime, $\tau_{s h}$, characterizes the rate of drying shrinkage and its dependence on effective thickness $D$ is based on the diffusion theory for drying. The parameter $\epsilon_{c e m}$ and the exponents $p_{\epsilon a}$, $p_{\epsilon w}$ and $p_{\epsilon c}$ are cement type dependent quantities and are specified in Table 1.
The value of the static elastic modulus ${ }^{1}$ at loading time $t^{\prime}$ should be calculated as

$$
E\left(t^{\prime}\right)=1 / J\left(t^{\prime}+\Delta, t^{\prime}\right)
$$

in which $\Delta=0.001$ day (this gives good agreement with the age dependence of $E$ according to the ACI formula for $E$ based on $f_{c}^{\prime}(t)$ for ages up to a few months, but for multi-year ages, the ACI, as well as fib, appear to underestimate the $E(t)$ growth significantly, which is seen in a plot of $E$ versus $\log t$ (rather than $E$ versus $t$ ).

The modulus growth according to ACI, modified to recover the 28 days value, is given by

$$
E(t)=E_{28} \sqrt{\frac{t}{4 \text { days }+(6 / 7) \mathrm{t}}}
$$

\footnotetext{
$\overline{1}$ Young's modulus $E(t)$ for creep cannot be properly defined without considering the time $\Delta$ during which the stress is applied, i.e., raised from 0 to the sustained value. In laboratory creep tests, $\Delta$ varies from $0.1 \mathrm{~s}$, when the load is applied by opening a valve in a hydraulic loading system, to as much as $1 \mathrm{~h}$ when the load is applied by a spring jacked up manually. Thus the elastic modulus for the initial deformation in a creep test should properly be defined by Eq. (18). Typically, $J\left(t^{\prime}+\Delta, t^{\prime}\right)$ increases by $17 \%$ when $\Delta$ is increased from $0.1 \mathrm{~s}$ to $1 \mathrm{~h}$. In ASTM, $E$ is defined by a standard test which involves loadingunloading cycles and it so happens that it is approximately equal to Eq. (18) when $\Delta=0.001$ day (or $1.5 \mathrm{~min}$ ). Does the arbitrariness in defining $\Delta$ matter for creep analysis based on the creep coefficient $\phi\left(t, t^{\prime}\right)$ ? Not at all, provided that, for a chosen $\Delta$, both $E(t)$ and $\phi\left(t, t^{\prime}\right)$ are calculated from compliance $J\left(t, t^{\prime}\right)$. But otherwise gross errors can arise, and have often arisen in this way. Eq. (18) also gives the age dependence of elastic modulus. In more detail, see discussion of Eqs. 1.46 and 1.47 in [7].
} 
Table 1 Shrinkage parameters depending on cement type for B4

\begin{tabular}{llll}
\hline Parameter & $\mathrm{R}$ & $\mathrm{RS}$ & $\mathrm{SL}$ \\
\hline$\tau_{c e m}$ (days) & 0.016 & 0.080 & 0.010 \\
$p_{\tau a}$ & -0.33 & -0.33 & -0.33 \\
$p_{\tau w}$ & -0.06 & -2.40 & 3.55 \\
$p_{\tau c}$ & -0.10 & -2.70 & 3.80 \\
$\epsilon_{c e m}$ & $360 \times 10^{-6}$ & $860 \times 10^{-6}$ & $410 \times 10^{-6}$ \\
$p_{\epsilon a}$ & -0.80 & -0.80 & -0.80 \\
$p_{\epsilon w}$ & 1.10 & -0.27 & 1.00 \\
$p_{\epsilon c}$ & 0.11 & 0.11 & 0.11 \\
\hline
\end{tabular}

Humidity dependence:

$$
k_{h}= \begin{cases}1-h^{3} & h \leq 0.98 \\ 12.94(1-h)-0.2 & 0.98 \leq h \leq 1\end{cases}
$$

for environmental conditions with $100 \%$ relative humidity the amount of potential water supply has to be taken into account: under water conditions should be captured by $k_{h}=-0.2$, which approximates swelling; for concrete exposed to fog (having also $100 \%$ humidity) it is better to use $h=0.98$ since normally fog cannot supply enough water to produce swelling.

Drying shrinkage halftime (note that the temperature effect is already included in $\tilde{t}$ ):

$$
\tau_{s h}=\tau_{0} k_{\tau a}\left(k_{s} \frac{D}{1 \mathrm{~mm}}\right)^{2}
$$

where the effective thickness $D=2 V / S$.

$$
\tau_{0}=\tau_{c e m}\left(\frac{a / c}{6}\right)^{p_{\tau a}}\left(\frac{w / c}{0.38}\right)^{p_{\tau w}}\left(\frac{6.5 c}{\rho}\right)^{p_{\tau c}}
$$

The aggregate type dependent correction factor $k_{\tau a}$ is defined in Table 6 and can be set to 1 if no information on the aggregate type exists. Parameter $\tau_{c e m}$ and the exponents $p_{\tau a}, p_{\tau w}$, and $p_{\tau c}$ are cement type dependent and are taken from Table 1 . The specimen geometry is captured by shape parameter $k_{s}$ :

$k_{s}= \begin{cases}1.00 & \text { infinite slab } \\ 1.15 & \text { infinite cylinder } \\ 1.25 & \text { infinite square prism } \\ 1.30 & \text { sphere } \\ 1.55 & \text { cube }\end{cases}$

Autogenous shrinkage equation: The autogenous shrinkage is the inelastic volumetric strain in a stressfree element at constant total water content. It is observed in sealed concrete specimens. It approximately equals the inelastic volumetric strain in the core of massive cross sections. The empirical function describing the autogenous shrinkage approximates the result of a large number of chemical reactions among the constituents of the mix. It gives a good estimate of the magnitude and evolution of the autogenous shrinkage contribution to the total shrinkage. Note that its definition does not include the volume change of fresh concrete within the first few hours before the set, which are not relevant to structural analysis.

$$
\epsilon_{a u}\left(\tilde{t}, \tilde{t}_{0}\right)=\epsilon_{a u \infty}\left[1+\left(\frac{\tau_{a u}}{\tilde{t}+\tilde{t}_{0}}\right)^{\alpha}\right]^{r_{t}}, \alpha=r_{\alpha}\left(\frac{w / c}{0.38}\right)
$$

Final autogenous shrinkage:

$$
\epsilon_{a u \infty}=-\epsilon_{a u, c e m}\left(\frac{a / c}{6}\right)^{r_{\epsilon a}}\left(\frac{w / c}{0.38}\right)^{r_{e w}}
$$

Autogenous shrinkage halftime:

$$
\tau_{a u}=\tau_{a u, c e m}\left(\frac{w / c}{0.38}\right)^{r_{\tau w}}
$$

The parameters $\epsilon_{a u, c e m}, \tau_{a u, c e m}$ as well as the exponents $r_{\epsilon a}, r_{\epsilon w}$, and $r_{\tau w}$ are taken from Table 2 .

Typical shrinkage curves as functions of drying time $t-t_{0}$ are given in Fig. 3. The top row presents the drying shrinkage contribution for a constant environmental humidity of $h=0.65$ and variable effective thickness $D=76,152,304,610 \mathrm{~mm}$ (left plots) as well as constant thickness $D=152 \mathrm{~mm}$ and variable environmental humidity $h=0.4,0.6,0.8$ (right plots). The unaffected contribution of autogenous shrinkage is plotted in the middle row. The last row shows the respective total shrinkage curves.

Table 2 Autogenous shrinkage parameters depending on cement type for B4

\begin{tabular}{llll}
\hline Parameter & $\mathrm{R}$ & $\mathrm{RS}$ & $\mathrm{SL}$ \\
\hline$\tau_{a u, c e m}$ (days) & 1.00 & 41.0 & 1.00 \\
$r_{\tau w}$ & 3.00 & 3.00 & 3.00 \\
$r_{t}$ & -4.50 & -4.50 & -4.50 \\
$r_{\alpha}$ & 1.00 & 1.40 & 1.00 \\
$\epsilon_{\text {au,cem }}$ & $210 \times 10^{-6}$ & $-84.0 \times 10^{-6}$ & $0.00 \times 10^{-6}$ \\
$r_{\epsilon a}$ & -0.75 & -0.75 & -0.75 \\
$r_{\epsilon w}$ & -3.50 & -3.50 & -3.50 \\
\hline
\end{tabular}



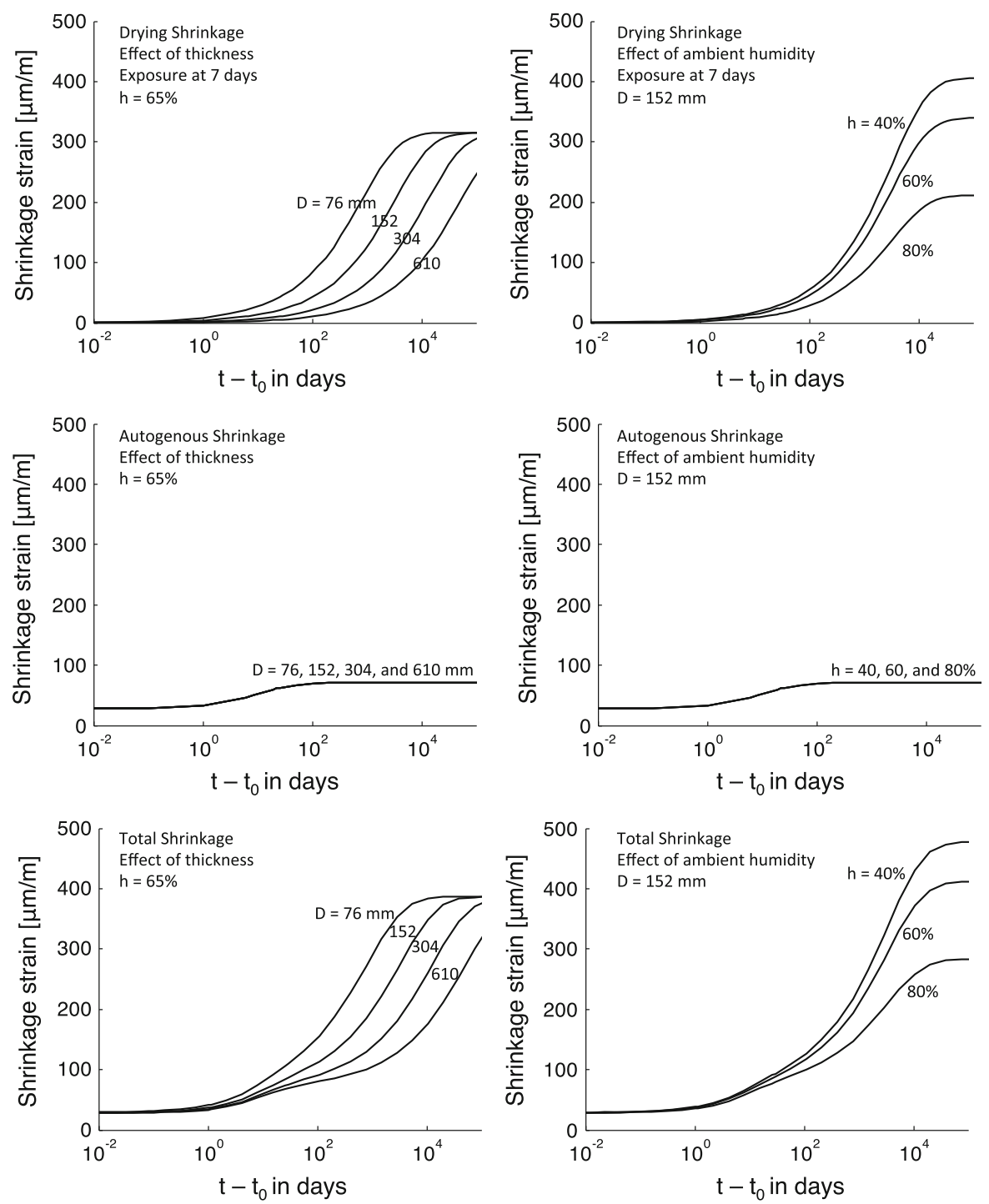

Fig. 3 Typical drying, autogenous, and total shrinkage curves, as a function of varying thickness and humidity given by the B4 model

\subsection{Average creep of a cross-section}

The total creep compliance function may be decomposed as

$$
J\left(\hat{t}, \hat{t}^{\prime}\right)=q_{1}+R_{T} C_{0}\left(\hat{t}, \hat{t}^{\prime}\right)+C_{d}\left(\hat{t}, \hat{t}^{\prime}, \tilde{t}_{0}\right)
$$

in which $q_{1}=$ the instantaneous compliance = compliance extrapolated from compliance curves between $0.1 \mathrm{~s}$ and $1 \mathrm{~h}$ to zero load duration, which is approximately independent of the age $t^{\prime}$ at loading; $C_{0}\left(\hat{t}, \hat{t}^{\prime}\right)=$ compliance function for basic creep (i.e., creep at constant moisture content and no moisture movement through the material); and $C_{d}\left(\hat{t}, \hat{t}, \tilde{t}_{0}\right)=$ additional compliance due to simultaneous drying.

Similar to model B3, the instantaneous compliance is approximated as:

$$
q_{1}=\frac{1}{E_{0}}=\frac{p_{1}}{E_{28}}
$$

where $p_{1}$ is a cement type dependent factor, defined in Table 3, and $E_{28}$ is the 28-day modulus that can be predicted from compressive strength using standard empirical relationships $[15,18]$ such as known from model B3: 
Table 3 Creep parameters depending on cement type for B4

\begin{tabular}{llll}
\hline Parameter & $\mathrm{R}$ & $\mathrm{RS}$ & $\mathrm{SL}$ \\
\hline$p_{1}$ & 0.70 & 0.60 & 0.80 \\
$p_{2}$ & $58.6 \times 10^{-3}$ & $17.4 \times 10^{-3}$ & $40.5 \times 10^{-3}$ \\
$p_{3}$ & $39.3 \times 10^{-3}$ & $39.3 \times 10^{-3}$ & $39.3 \times 10^{-3}$ \\
$p_{4}$ & $3.4 \times 10^{-3}$ & $3.4 \times 10^{-3}$ & $3.4 \times 10^{-3}$ \\
$p_{5}$ & $777 \times 10^{-6}$ & $94.6 \times 10^{-6}$ & $496 \times 10^{-6}$ \\
$p_{5 H}$ & 8.00 & 1.00 & $8.00^{*}$ \\
$p_{2 w}$ & 3.00 & 3.00 & 3.00 \\
$p_{3 a}$ & -1.10 & -1.10 & -1.10 \\
$p_{3 w}$ & 0.40 & 0.40 & 0.40 \\
$p_{4 a}$ & -0.90 & -0.90 & -0.90 \\
$p_{4 w}$ & 2.45 & 2.45 & 2.45 \\
$p_{5 \epsilon}$ & -0.85 & -0.85 & -0.85 \\
$p_{5 a}$ & -1.00 & -1.00 & -1.00 \\
$p_{5 w}$ & 0.78 & 0.78 & 0.78 \\
$* \ldots$ & lacking data, assumed & & \\
\hline
\end{tabular}

$E_{28}=4734 \mathrm{MPa} \sqrt{\frac{\bar{f}_{c}}{\mathrm{MPa}}}$

The basic creep compliance is more conveniently defined by its time rate than its value as given by [6]:

$$
\begin{aligned}
\dot{C}_{0}\left(t, t^{\prime}\right)= & \frac{n\left(q_{2} t^{-m}+q_{3}\right)}{\left(t-t^{\prime}\right)+\left(t-t^{\prime}\right)^{1-n}} \\
& +\frac{q_{4}}{t}(m=0.5, n=0.1)
\end{aligned}
$$

in which $\dot{C}_{0}\left(t, t^{\prime}\right)=\partial C_{0}\left(t, t^{\prime}\right) / \partial t, t$ and $t^{\prime}$ must be in days, $m$ and $n$ are empirical parameters whose value can be taken the same for all normal concretes as indicated above ( $m=0.5$ and $n=0.1$ ). For step-bystep computer structural analysis, the compliance is needed only in the foregoing rate form. When the total basic creep compliance is needed, it may be written as follows:

$$
\begin{aligned}
C_{0}\left(\hat{t}, \hat{t}^{\prime}\right)= & q_{2} Q\left(\hat{t}, \hat{t}^{\prime}\right)+q_{3} \ln \left[1+\left(\frac{\hat{t}-\hat{t}^{\prime}}{1 \text { day }}\right)^{0.1}\right] \\
& +q_{4} \ln \left(\frac{\hat{t}}{\hat{t}^{\prime}}\right)
\end{aligned}
$$

$Q\left(\hat{t}, \hat{t}^{\prime}\right)$ is a binomial integral which cannot be expressed analytically, but can be calculated from the following approximate explicit formula [6]:

$$
\begin{aligned}
& Q\left(\hat{t}, \hat{t}^{\prime}\right)=Q_{f}\left(\hat{t}^{\prime}\right)\left(1+\left(\frac{Q_{f}\left(\hat{t}^{\prime}\right)}{Z\left(\hat{t}, \hat{t}^{\prime}\right)}\right)^{r\left(\hat{t}^{\prime}\right)}\right)^{-\frac{1}{r\left(\hat{t}^{\prime}\right)}} \\
& Q_{f}\left(\hat{t}^{\prime}\right)=\left[0.086\left(\frac{\hat{t}^{\prime}}{1 \text { day }}\right)^{2 / 9}+1.21\left(\frac{\hat{t}^{\prime}}{1 \text { day }}\right)^{4 / 9}\right]^{-1} \\
& Z\left(\hat{t}^{\prime}\right)=\left(\frac{\hat{t}^{\prime}}{1 \text { day }}\right)^{-0.5} \ln \left[1+\left(\frac{\hat{t}-\hat{t}^{\prime}}{1 \text { day }}\right)^{0.1}\right] \\
& r\left(\hat{t}^{\prime}\right)=1.7\left(\frac{\hat{t}^{\prime}}{1 \text { day }}\right)^{0.12}+8
\end{aligned}
$$

The drying creep compliance term is given by

$$
\begin{aligned}
C_{d}\left(\hat{t}, \hat{t}, \tilde{t}_{0}\right)= & q_{5}\left\langle\exp \left[-p_{5 H} H\left(\hat{t}, \tilde{t}_{0}\right)\right]\right. \\
& \left.-\exp \left[-p_{5 H} H_{c}\left(\hat{t}_{0}, \tilde{t}_{0}\right)\right]\right\rangle^{0.5}
\end{aligned}
$$

where $\quad \hat{t}_{0}=\max \left(\hat{t}, \tilde{t}_{0}\right) \quad$ if $\quad \hat{t} \geq \hat{t}_{0} ; \quad$ otherwise $C_{d}\left(\hat{t}, \hat{t}^{\prime}, \tilde{t}_{0}\right)=0$

$H\left(\hat{t}, \tilde{t}_{0}\right)=1-(1-h) \tanh \sqrt{\frac{\hat{t}-\tilde{t}_{0}}{\tau_{s h}}}$

$H_{c}\left(\hat{t}_{0}, \tilde{t}_{0}\right)=1-(1-h) \tanh \sqrt{\frac{\tilde{t}_{0}^{\prime}-\tilde{t}_{0}}{\tau_{s h}}}$

where $\langle\mathbf{u}\rangle=\max (\mathbf{u}, \mathbf{0})$ (Macauley brackets). The effects of temperature are accounted for by the concept of an acceleration of time (horizontal scaling), combined with vertical scaling by the factor:

$R_{T}=\exp \left[\frac{U_{c}^{\prime}}{R}\left(\frac{1}{293}-\frac{1}{T+273}\right)\right]$

where $U_{c}^{\prime}$ is the effective activation energy for creep (if no information is available $U_{c}^{\prime}=U_{c}$ ), and $R=$ gas constant as formulated in [19] and supported by several experimental studies [20, 21].

Typical creep compliance curves are given in Fig. 4. The first row shows the basic creep compliance for ages of loading of $t^{\prime}=7,70,700$ days, on the left for an environmental humidity of $h=0.40$ and on the right side for $h=0.65$. The middle row presents the respective drying creep contribution followed by the total creep compliance curves in the bottom row. 

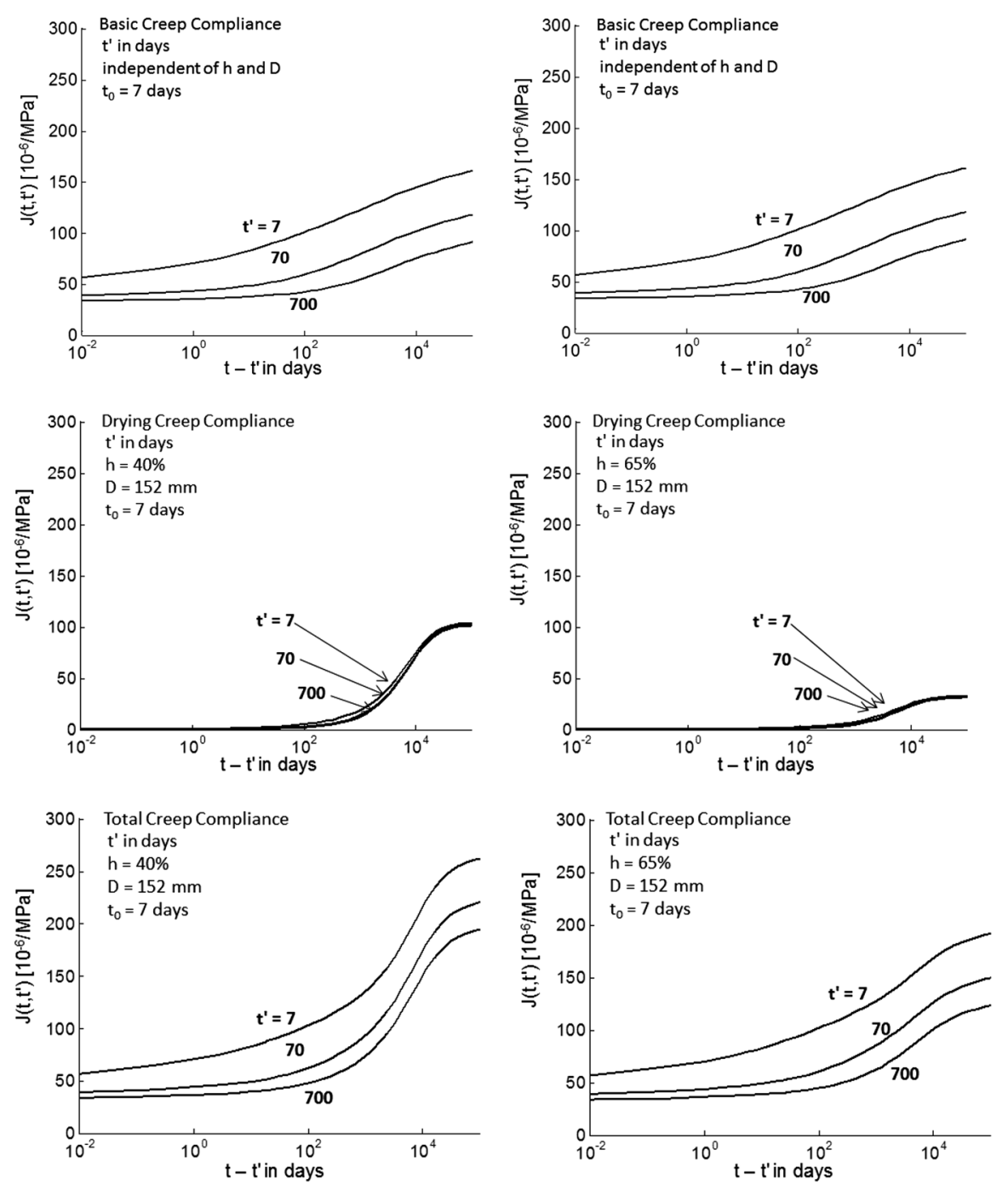

Fig. 4 Typical basic, drying, and total creep curves, as a function of loading age for two humidities given by the B4 model

\subsection{Model parameters}

Since the theoretical understanding of the mechanisms by which concrete composition and strength affect creep and shrinkage is rather limited, semiempirical relationships for the parameters of various creep and shrinkage components have been sought. They have been calibrated by statistical optimization of the fit of the new NU database [22, 23], and read as follows.

Aging viscoelastic creep:

$$
q_{2}=\frac{p_{2}}{1 \mathrm{GPa}}\left(\frac{w / c}{0.38}\right)^{p_{2 w}}
$$

Non-aging viscoelastic creep:

$$
q_{3}=p_{3} q_{2}\left(\frac{a / c}{6}\right)^{p_{3 a}}\left(\frac{w / c}{0.38}\right)^{p_{3 w}}
$$

Flow:

$$
q_{4}=\frac{p_{4}}{1 \mathrm{GPa}}\left(\frac{a / c}{6}\right)^{p_{4 a}}\left(\frac{w / c}{0.38}\right)^{p_{4 w}}
$$


Drying creep:

$$
q_{5}=\frac{p_{5}}{1 \mathrm{GPa}}\left(\frac{a / c}{6}\right)^{p_{5 a}}\left(\frac{w / c}{0.38}\right)^{p_{5 w}}\left|k_{h} \epsilon_{s h \infty}\left(\tilde{t}_{0}\right)\right|^{p_{5 \epsilon}}
$$

The parameters in Equs. 40 to 43 are for the most part cement type dependent and can be taken from Table 3 .

The Model Code cement types R-normal, RS-rapid hardening, and SL-slow hardening classification system has been selected since it captures the reactivity leading to the hydration reaction. While it do not directly correspond to application based cement classifications, if reactivity information is available, an approximate correspondence may be made. For example, ASTM Type I general purpose portland cement may be assumed as type R reactivity. ASTM Type II is a low heat cement and may be considered as SL. Type III, high early heat cements can be assumed as RS. Types IV, V, Ia, IIa, and IIIa should be mapped to by their reactivity in the Model Code classification Table and any admixtures which are part of their composition should be considered based on their proportions. The model considers all admixtures and reactive additives such as fly ash separately.

\subsection{Parameters for various types of admixtures and aggregates}

If the details of concrete composition, especially the types of admixtures and aggregates, are known, they can be considered to improve the prediction. By statistical optimization of the fit of the new NU database, the following parameters have been obtained. Note that not all the trends of the commercially available admixtures and additives could have been investigated, because of insufficient data.

A complicating feature is that, in the case of multiple admixtures, a number of potentially interacting chemical reactions may be affecting the volume change. In absence of a full chemical model, the effects of specific admixtures and their interactions have been ranked empirically. The first applicable class according to Tables 4 and 5 should be selected, as it represents the most likely effects governing the long-term shrinkage and creep.

The effect of aggregate type is taken care of by correction factors $k_{\tau a}$ for shrinkage halftime and $k_{\epsilon a}$ for final shrinkage in Eqs. 17 and 21 as defined in Table 6.
1.8 Strength-based model for simplified design (B4s)

Even if the concrete composition for a given structure has not yet been decided, it is usually known what the typical concrete composition in a given geographical area is. Nevertheless, engineers may wish to estimate creep and shrinkage solely from the chosen required strength $f_{c}^{\prime}$ of concrete to be used in the structure. Most of the existing creep and shrinkage recommendations of engineering societies are formulated that way (Table 7, 8, 9). Therefore, by means of statistical optimization of the fit of the new NU database, a simplified variant of model B4 using the mean compressive strength $\bar{f}_{c}$ has been developed (it should be noted that the average strength, $\bar{f}_{c}$, is significantly higher than $f_{c}^{\prime}$; typically, $\bar{f}_{c} \approx f_{c}^{\prime}+8.3 \mathrm{MPa}$ [18] or $\bar{f}_{c} \approx f_{c}^{\prime}+8 \mathrm{MPa}$ [24])

Shrinkage:

$$
\epsilon_{0}=\epsilon_{s, c e m}\left(\frac{\bar{f}_{c}}{40 \mathrm{MPa}}\right)^{s_{f f}}
$$

Drying shrinkage halftime

$$
\tau_{0}=\tau_{s, c e m} \text { days }\left(\frac{\bar{f}_{c}}{40 \mathrm{MPa}}\right)^{s_{\tau f}}
$$

Autogenous shrinkage

$$
\epsilon_{a u}\left(\tilde{t}, \tilde{t}_{0}\right)=\epsilon_{a u \infty}\left[1+\left(\frac{\tau_{a u}}{\tilde{t}+\tilde{t}_{0}}\right)^{\alpha_{s}}\right]^{r_{t}}
$$

Final autogenous shrinkage:

$$
\epsilon_{a u \infty}=-\epsilon_{a u, c e m}\left(\frac{\bar{f}_{c}}{40 \mathrm{MPa}}\right)^{r_{f}}
$$

Autogenous shrinkage halftime:

$$
\tau_{a u}=\tau_{a u, c e m} \text { days }\left(\frac{\bar{f}_{c}}{40 \mathrm{MPa}}\right)^{r_{\tau f}}
$$

Aging viscoelastic creep

$$
q_{2}=\frac{s_{2}}{1 \mathrm{GPa}}\left(\frac{\bar{f}_{c}}{40 \mathrm{MPa}}\right)^{s_{2 f}}
$$

Non-aging viscoelastic creep

$$
q_{3}=s_{3} q_{2}\left(\frac{\bar{f}_{c}}{40 \mathrm{MPa}}\right)^{s_{3 f}}
$$


Table 4 Admixture dependent parameter scaling factors for shrinkage for B4
Re retarder, Fly fly ash,

Super superplasticizer, Silica silica fume, AEA air entraining agent, $W R$ water reducer

* Lacking data, assumed

\begin{tabular}{|c|c|c|c|c|}
\hline Admixture class ( $\%$ of c) & $\times \tau_{c e m}$ & $\times \epsilon_{a u, c e m}$ & $\times r_{\epsilon w}$ & $\times r_{\alpha}$ \\
\hline $\operatorname{Re}(\leq 0.5), \operatorname{Fly}(\leq 15)$ & 6.00 & 0.58 & 0.50 & 2.60 \\
\hline $\operatorname{Re}(>0.5, \leq 0.6), \operatorname{Fly}(\leq 15)$ & 2.00 & 0.43 & 0.59 & 3.10 \\
\hline $\operatorname{Re}(>0.5, \leq 0.6), \operatorname{Fly}(>15, \leq 30)$ & 2.10 & 0.72 & 0.88 & 3.40 \\
\hline $\operatorname{Re}(>0.5, \leq 0.6)$, Fly $(>30)$ & 2.80 & 0.87 & 1.60 & 5.00 \\
\hline $\operatorname{Re}(>0.6), \operatorname{Fly}(\leq 15)$ & 2.00 & 0.26 & 0.22 & 0.95 \\
\hline $\operatorname{Re}(>0.6), \operatorname{Fly}(>15, \leq 30)$ & 2.10 & 1.10 & 1.10 & 3.30 \\
\hline $\operatorname{Re}(>0.6), \operatorname{Fly}(>30)$ & $2.10^{*}$ & 1.10 & 0.97 & 4.00 \\
\hline Fly $(\leq 15)$, Super $(\leq 5)$ & 0.32 & 0.71 & 0.55 & 1.71 \\
\hline Fly $(\leq 15)$, Super $(>5)$ & $0.32 *$ & 0.55 & 0.92 & 2.30 \\
\hline Fly $(>15, \leq 30)$, Super $(\leq 5)$ & 0.50 & 0.90 & 0.82 & 1.25 \\
\hline Fly $(>15, \leq 30)$, Super $(>5)$ & $0.50 *$ & 0.80 & 0.80 & 2.81 \\
\hline Fly $(>30)$, Super $(\leq 5)$ & 0.63 & 1.38 & 0.00 & 1.20 \\
\hline Fly $(>30)$, Super $(>5)$ & $0.63 *$ & 0.95 & 0.76 & 3.11 \\
\hline $\operatorname{Super}(\leq 5)$, Silica $(\leq 8)$ & 6.00 & 2.80 & 0.29 & 0.21 \\
\hline $\operatorname{Super}(\leq 5), \operatorname{Silica}(\geq 8)$ & 3.00 & 0.96 & 0.26 & 0.71 \\
\hline $\operatorname{Super}(\geq 5)$, Silica $(\leq 8)$ & 8.00 & 1.95 & 0.00 & 1.00 \\
\hline Silica $(\leq 8)$ & 1.90 & 0.47 & 0.00 & 1.20 \\
\hline Silica $(>8, \leq 18)$ & 2.60 & 0.82 & 0.00 & 1.20 \\
\hline Silica $(>18)$ & 1.00 & 1.50 & 5.00 & 1.00 \\
\hline $\operatorname{AEA}(\leq 0.05)$ & 2.30 & 1.10 & 0.28 & 0.35 \\
\hline $\operatorname{AEA}(>0.05)$ & 0.44 & 4.28 & 0.00 & 0.36 \\
\hline $\mathrm{WR}(\leq 2)$ & 0.50 & 0.38 & 0.00 & 1.90 \\
\hline $\mathrm{WR}(>2, \leq 3)$ & 6.00 & 0.45 & 1.51 & 0.30 \\
\hline $\mathrm{WR}(>3)$ & 2.40 & 0.40 & 0.68 & 1.40 \\
\hline
\end{tabular}

Drying creep

Table 5 Admixture dependent parameter scaling factors for creep for B4

\begin{tabular}{lllll}
\hline Admixture class $(\%$ of $c)$ & $\times p_{2}$ & $\times p_{3}$ & $\times p_{4}$ & $\times p_{5}$ \\
\hline $\operatorname{Re}(\leq 0.5)$, Fly $(\leq 15)$ & 0.31 & 7.14 & 1.35 & 0.48 \\
$\operatorname{Re}(>0.5)$, Fly $(\leq 15)$ & 1.43 & 0.58 & 0.90 & 0.46 \\
$\operatorname{Fly}(\geq 15)$ & 0.37 & 2.33 & 0.63 & 1.60 \\
Super $(\geq 0)$ & 0.72 & 2.19 & 1.72 & 0.48 \\
$\operatorname{Silica}(\geq 0)$ & 1.12 & 3.11 & 0.51 & 0.61 \\
$\operatorname{AEA}(\geq 0)$ & 0.90 & 3.17 & 1.00 & 0.10 \\
$\operatorname{WR}(\leq 2)$ & 1.00 & 2.10 & 1.68 & 0.45 \\
$\operatorname{WR}(>2, \leq 3)$ & 1.41 & 0.72 & 1.76 & 0.60 \\
$\operatorname{WR}(>3)$ & 1.28 & 2.58 & 0.73 & 1.10 \\
\hline
\end{tabular}

Re retarder, Fly fly ash, Super superplasticizer, Silica silica fume, $A E A$ air entraining agent, $W R$ water reducer

Flow

$q_{4}=\frac{s_{4}}{1 \mathrm{GPa}}\left(\frac{\bar{f}_{c}}{40 \mathrm{MPa}}\right)^{s_{4 f}}$ $q_{5}=\frac{s_{5}}{1 \mathrm{GPa}}\left(\frac{\bar{f}_{c}}{40 \mathrm{MPa}}\right)^{s_{5 f}}\left|k_{h} \epsilon_{s h \infty}\right|^{p_{5 \epsilon}}$

\subsection{Example of calculation using model B4}

The user may check the correctness of his programming of model B4 and B4s by a comparison with the following examples. These examples are based on selected test data from [25]. Calculations are made with four-digit accuracy so that the programming may be checked dependably, even though such accuracy is not justified by experimental scatter.

For a composition based prediction of creep and shrinkage consider the following given properties: (1) Type I cement concrete (R); (2) age of concrete $t=112$ days; (3) age at loading $t^{\prime}=28$ days; (4) age when drying begins $t_{0}=28$ days; (5) relative humidity $h=50 \%$; (6) mean cylinder 
Table 6 Aggregate dependent parameter scaling factors for shrinkage for B4

* denotes uncertain fitted parameters; details on the statistical analysis are presented in [22]

\begin{tabular}{lllll}
\hline Aggregate type & $k_{\tau a}$ & $k_{\epsilon a}$ & Young's Modulus $E_{\text {agg }}(\mathrm{GPa})$ & Density $\rho_{\text {agg }}\left(\mathrm{g} / \mathrm{cm}^{3}\right)$ \\
\hline Diabase & $0.06^{*}$ & $0.76^{*}$ & $70-90$ & $2.8-3.0$ \\
Quartzite & 0.59 & 0.71 & $50-90$ & $2.5-2.8$ \\
Limestone & 1.80 & 0.95 & $10-70$ & $1.8-2.9$ \\
Sandstone & 2.30 & 1.60 & $10-50$ & $2.0-2.8$ \\
Granite & 4.00 & 1.05 & $30-70$ & $2.5-2.8$ \\
Quartz Diorite & $15.0^{*}$ & $2.20^{*}$ & $50-100$ & $2.7-3.1$ \\
\hline
\end{tabular}

Table 7 Autogenous shrinkage parameters for B4s for regular cement (R), rapid hardening cement (RS), and slow hardening cement (SL)

\begin{tabular}{ll}
\hline Parameter & $\mathrm{R}, \mathrm{RS}, \mathrm{SL}$ \\
\hline$\tau_{\text {au,cem }}$ & 2.26 \\
$r_{\tau f}$ & 0.27 \\
$\epsilon_{\text {au,cem }}$ & $78.2 \times 10^{-6}$ \\
$r_{\epsilon f}$ & 1.03 \\
$\alpha_{s}$ & 1.73 \\
$r_{t}$ & -1.73 \\
\hline
\end{tabular}

Table 8 Shrinkage parameters depending on cement type for B4s

\begin{tabular}{llll}
\hline Parameter & $\mathrm{R}$ & $\mathrm{RS}$ & $\mathrm{SL}$ \\
\hline$\tau_{s, \text { cem }}$ & 0.027 & 0.027 & 0.032 \\
$s_{\tau f}$ & 0.21 & 1.55 & -1.84 \\
$\epsilon_{s, \text { cem }}$ & $590 \times 10^{-6}$ & $830 \times 10^{-6}$ & $640 \times 10^{-6}$ \\
$s_{\epsilon f}$ & -0.51 & -0.84 & -0.69 \\
\hline
\end{tabular}

compressive strength $\bar{f}_{c}=27.6 \mathrm{MPa}$; (7) volumesurface ratio $V / S=19.05 \mathrm{~mm}$; (8) cement content $c=219.3 \mathrm{~kg} / \mathrm{m}^{3}$; (9) water-cement ratio $w / c=0.60$; (10) aggregate-cement ratio $a / c=7.0$; (11) applied compressive stress $\sigma=11.03 \mathrm{MPa}$.

$E_{28}=4734 \sqrt{27.6} \mathrm{MPa}=24.87 \mathrm{GPa} \quad$ [Eq. 29]
Table 9 Creep parameters depending on cement type for B4s

\begin{tabular}{llll}
\hline Parameter & $\mathrm{R}$ & $\mathrm{RS}$ & $\mathrm{SL}$ \\
\hline$s_{2}$ & $14.2 \times 10^{-3}$ & $29.9 \times 10^{-3}$ & $11.2 \times 10^{-3}$ \\
$s_{3}$ & 0.976 & 0.976 & 0.976 \\
$s_{4}$ & $4.00 \times 10^{-3}$ & $4.00 \times 10^{-3}$ & $4.00 \times 10^{-3}$ \\
$s_{5}$ & $1.54 \times 10^{-3}$ & $41.8 \times 10^{-6}$ & $150 \times 10^{-6}$ \\
$s_{2 f}$ & -1.58 & -1.58 & -1.58 \\
$s_{3 f}$ & -1.61 & -1.61 & -1.61 \\
$s_{4 f}$ & -1.16 & -1.16 & -1.16 \\
$s_{5 f}$ & -0.45 & -0.45 & -0.45 \\
\hline
\end{tabular}

$\begin{aligned} \tau_{0} & =0.016 \text { days } \times 0.9504 \times 0.9730 \times 1.051 \\ & =15.55 \times 10^{-3} \text { days }\end{aligned}$

[Eq. 22, Table 1]

$$
\begin{aligned}
\tau_{s h}= & 15.55 \times 10^{-3} \text { days } \\
& \times\left(1 \mathrm{~mm}^{-1} \times 2 \times 19.05 \mathrm{~mm}\right)^{2} \\
= & 22.58 \text { days } \quad[\text { Eq. } 21]
\end{aligned}
$$

$$
\begin{aligned}
\epsilon_{0} & =360 \times 10^{-6} \times 0.8840 \times 1.653 \times 0.9465 \\
& =497.8 \times 10^{-6} \quad[\text { Eq. } 16, \text { Table } 1]
\end{aligned}
$$$$
E(607)=24.87 \mathrm{GPa} \sqrt{\frac{607 \text { days }}{4 \text { days }+(6 / 7) 607 \text { days }}}
$$
$=26.76 \mathrm{GPa} \quad$ [updated ACI, see Eq. 19]

$E\left(t_{0}+\tau_{s h}\right)=24.87 \mathrm{GPa} \sqrt{\frac{28 \text { days }+22.578 \text { days }}{4 \text { days }+(6 / 7)(28 \text { days }+22.578 \text { days })}}=25.70 \mathrm{GPa} \quad$ [updated ACI, see Eq. 19] 


$$
\begin{aligned}
\epsilon_{\text {sh } \infty} & =-497.8 \times 10^{-6} \times 26.76 \mathrm{GPa} \div 25.70 \mathrm{GPa} \\
& =-518.3 \times 10^{-6} \quad[\text { Eq. 17] }
\end{aligned}
$$

$S_{t}=\tanh \sqrt{\frac{112 \text { days }-28 \text { days }}{22.578 \text { days }}}=0.9586 \quad$ [Eq. 15]

$k_{h}=1-0.5^{3}=0.8750 \quad$ [Eq. 20]

$$
\begin{aligned}
\epsilon_{\text {sh }} & =-518.3 \times 10^{-6} \times 0.8750 \times 0.9586 \\
& =-434.7 \times 10^{-6} \quad \text { [Eq. 14] }
\end{aligned}
$$$$
\epsilon_{\text {au } \infty}=-210 \times 10^{-6} \times 0.8908 \times 0.2022
$$$$
=-37.82 \times 10^{-6} \quad[\text { Eq. 25, Table 2] }
$$

$\tau_{a u}=1$ day $\times 3.936=3.936$ days $\quad$ [Eq. 26, Table 2]

$\epsilon_{a u}=-37.82 \times 10^{-6}\left[1+(0.0352)^{1.579}\right]^{-4.5}$

$=-36.97 \times 10^{-6} \quad$ [Eq. 24, Table 2]

$q_{1}=0.7 \div 24.87 \mathrm{GPa}=28.15 \times 10^{-6} / \mathrm{MPa}$

[Eq. 28, Table 3]

$$
\begin{aligned}
q_{2}= & 58.6 \times 10^{-3} \times 3.936 / \mathrm{GPa} \\
= & 230.7 \times 10^{-6} / \mathrm{MPa} \quad[\text { Eq. 40, Table 3 }] \\
q_{3}= & 39.3 \times 10^{-3} \times 230.7 \times 10^{-6} \times 0.8440 \\
& \times 1.200 / \mathrm{MPa}=9.185 \times 10^{-6} / \mathrm{MPa}
\end{aligned}
$$

[Eq. 41, Table 3]

$$
\begin{aligned}
q_{4} & =3.4 \times 10^{-3} \times 0.8705 \times 3.062 / \mathrm{GPa} \\
& =9.062 \times 10^{-6} / \mathrm{MPa} \quad[\text { Eq. } 42, \text { Table 3] }
\end{aligned}
$$

$r=1.7 \times 1.492+8=10.54 \quad[$ Eq. 35]

$Z=0.1890 \times \ln (1+1.557)=0.1775 \quad$ [Eq. 34]

$$
\begin{aligned}
Q_{f} & =(0.086 \times 2.097+1.21 \times 4.397)^{-1} \\
& =0.1818 \quad[\text { Eq. 33] }
\end{aligned}
$$

$Q=0.1818(1+1.289)^{-0.095}=0.1681 \quad[$ Eq. 32]

$$
\begin{aligned}
C_{0}= & (230.7 \times 0.1681+9.185 \times 0.9390+9.062 \\
& \times 1.386) \times 10^{-6} / \mathrm{MPa}=59.95 \times 10^{-6} / \mathrm{MPa}
\end{aligned}
$$

[Eq. 31]

$$
\begin{aligned}
q_{5} & =777 \times 10^{-6} / \mathrm{GPa} \times 0.8571 \times 1.428 \times 694.9 \\
& =660.9 \times 10^{-6} / \mathrm{MPa} \quad[\text { Eq. } 43, \text { Table } 3]
\end{aligned}
$$

$S_{t_{c}}=0 . \quad$ [Eq. 15]

$$
\begin{aligned}
& H_{t}=1-0.5 \times 0.959=0.5207 \quad \text { [Eq. 37] } \\
& H_{t_{c}}=1-0.5 \times 0=1 . \quad \text { [Eq. 38] } \\
& \hat{t}_{0}^{\prime}=\tilde{t}_{0} \\
& C_{d}=660.9 \times 10^{-6} / \mathrm{MPa}\left\langle 0.016-3.355 \times 10^{-4}\right\rangle^{0.5} \\
& =81.44 \times 10^{-6} / \mathrm{MPa} \quad \text { [Eq. 36] } \\
& J=(28.15+59.95+81.44) \times 10^{-6} / \mathrm{MPa} \\
& =169.5 \times 10^{-6} / \mathrm{MPa} \quad \text { [Eq. 27] } \\
& \epsilon=-1870 \times 10^{-6}-434.7 \times 10^{-6}-36.97 \\
& \times 10^{-6}=-2342 \times 10^{-6} \quad \text { [Eq. } 12 \text { and 13] }
\end{aligned}
$$

If the same designer additionally knew that a combination of fly ash (15-30\% per unit weight of cement) would be added to the mix, then

$\tau_{0}=0.008$ days $\times 0.9504 \times 0.9730$

$$
\times 1.051=77.77 \times 10^{-4} \text { days }
$$

[Eq. 22, Table 1, Table 4]

$$
\begin{aligned}
\tau_{s h} & =77.77 \times 10^{-4} \text { days } \times\left(1 \mathrm{~mm}^{-1} \times 2 \times 19.05 \mathrm{~mm}\right)^{2} \\
& =11.29 \text { days } \quad[\text { Eq. } 21]
\end{aligned}
$$

$$
\begin{aligned}
\epsilon_{s h} & =-524.5 \times 10^{-6} \times 0.8750 \times 0.9915 \\
& =-455.1 \times 10^{-6} \quad[\text { Eq. 14] } \\
\epsilon_{a u \infty} & =-189.0 \times 10^{-6} \times 0.8908 \times 0.2696 \\
& =-45.39 \times 10^{-6} \quad[\text { Eq. 25, Table 2, Table 4] }
\end{aligned}
$$




$$
\begin{aligned}
\epsilon_{a u}= & -45.39 \times 10^{-6}\left[1+(0.0352)^{1.974}\right]^{-4.5} \\
= & -45.11 \times 10^{-6} \quad[\text { Eq. 24, Table 2, Table 4] } \\
q_{2}= & (58.6 \times 0.37) \times 10^{-3} \times 3.936 / \mathrm{GPa} \\
= & 85.35 \times 10^{-6} / \mathrm{MPa} \quad[\text { Eq. 40, Table 3, Table 5] } \\
q_{3}= & (39.3 \times 2.33) \times 10^{-3} \times 199.6 \times 10^{-6} \times \\
& 0.8440 \times 1.200 / \mathrm{MPa}=7.919 \times 10^{-6} / \mathrm{MPa}
\end{aligned}
$$

[Eq. 41, Table 3, Table 5]

$$
\begin{aligned}
q_{4}= & (3.40 \times 0.63) \times 10^{-3} \times 0.870 \times 3.062 / \mathrm{GPa} \\
= & 5.709 \times 10^{-6} / \mathrm{MPa} \quad[\text { Eq. } 42, \text { Table } 3, \text { Table 5] } \\
C_{0}= & (85.35 \times 0.1680+7.919 \times 0.9390+5.709 \\
& \times 1.386) \times 10^{-6} / \mathrm{MPa}=29.69 \times 10^{-6} / \mathrm{MPa}
\end{aligned}
$$

[Eq. 31]

$$
\begin{aligned}
q_{5}= & (777.0 \times 1.6) \times 10^{-6} / \mathrm{GPa} \times 1.6 \times 0.8571 \\
& \times 1.428 \times 614.0=934.4 \times 10^{-6} / \mathrm{MPa}
\end{aligned}
$$

[Eq. 43, Table 3, Table 5]

$$
\begin{aligned}
C_{d} & =934.4 \times 10^{-6} / \mathrm{MPa}\left\langle 0.018-3.355 \times 10^{-4}\right\rangle^{0.5} \\
& =123.1 \times 10^{-6} / \mathrm{MPa} \quad[\text { Eq. 36] } \\
J & =(28.15+29.69+123.1) \times 10^{-6} / \mathrm{MPa} \\
& =181.0 \times 10^{-6} / \mathrm{MPa} \quad[\text { Eq. 27] } \\
\epsilon & =-1996 \times 10^{-6}-455.1 \times 10^{-6}-45.11 \times 10^{-6} \\
& =-2496 \times 10^{-6} \quad[\text { Eqs. } 12 \text { and 13] }
\end{aligned}
$$

Now consider the situation when the designer knows only the compressive strength of the concrete using model B4s:

$$
\tau_{0}=0.027 \text { days } \times 0.925=24.98 \times 10^{-3} \text { days }
$$

[Eq. 45, Table 8]

$$
\begin{aligned}
\tau_{s h} & =24.98 \times 10^{-3} \text { days } \times\left(1 \mathrm{~mm}^{-1} \times 2 \times 19.05 \mathrm{~mm}\right)^{2} \\
& =36.26 \text { days } \quad[\text { Eq. 21] } \\
\epsilon_{0} & =590 \times 10^{-6} \times 1.208=712.9 \times 10^{-6}
\end{aligned}
$$

[Eq. 44, Table 8]

$$
\begin{aligned}
\epsilon_{s h \infty} & =-712.9 \times 10^{-6} \times 26.76 \mathrm{GPa} \div 25.94 \mathrm{GPa} \\
& =-735.5 \times 10^{-6} \quad[\text { Eq. 17] }
\end{aligned}
$$

$$
\begin{aligned}
\epsilon_{s h} & =-735.5 \times 10^{-6} \times 0.8750 \times 0.9090 \\
& =-585.1 \times 10^{-6} \quad \text { [Eq. 14] }
\end{aligned}
$$

$$
\begin{aligned}
\epsilon_{a u} & =-53.36 \times 10^{-6}\left[1+(0.0183)^{1.73}\right]^{-1.73} \\
& =-53.27 \times 10^{-6} \quad[\text { Eq. 46] }
\end{aligned}
$$

$$
\begin{aligned}
q_{2} & =14.2 \times 10^{-3} \times 1.797 / \mathrm{GPa} \\
& =25.52 \times 10^{-6} / \mathrm{MPa} \quad[\text { Eq. } 49, \text { Table 9] } \\
q_{3} & =0.976 \times 25.52 \times 10^{-6} \times 1.817 / \mathrm{MPa} \\
& =45.27 \times 10^{-6} / \mathrm{MPa} \quad[\text { Eq. } 50, \text { Table 9] }
\end{aligned}
$$$$
q_{4}=6.9 \times 10^{-3} \times 1.538 / \mathrm{GPa}
$$$$
=10.61 \times 10^{-6} / \mathrm{MPa} \quad[\text { Eq. } 51, \text { Table 9] }
$$

$$
\begin{aligned}
C_{0}= & (25.52 \times 0.1681+45.27 \times 0.9390+10.61 \\
& \times 1.386) \times 10^{-6} / \mathrm{MPa}=61.51 \times 10^{-6} / \mathrm{MPa}
\end{aligned}
$$

[Eq. 31]

$$
\begin{aligned}
q_{5} & =1540 \times 10^{-6} / \mathrm{GPa} \times 1.182 \times 516.0 \\
& =939.1 \times 10^{-6} / \mathrm{MPa} \quad[\text { Eq. 52, Table 9] } \\
C_{d} & =939.1 \times 10^{-6} / \mathrm{MPa}\left\langle 0.010-3.355 \times 10^{-4}\right\rangle^{0.5} \\
& =104.6 \times 10^{-6} / \mathrm{MPa} \quad[\text { Eq. 36] } \\
J & =(28.15+61.51+104.6) \times 10^{-6} / \mathrm{MPa} \\
& =194.2 \times 10^{-6} / \mathrm{MPa} \quad[\text { Eq. 27] } \\
\epsilon & =-2142 \times 10^{-6}-585.1 \times 10^{-6}-53.3 \times 10^{-6} \\
& =-2780 \times 10^{-6} \quad[\text { Eq. } 12 \text { and } 13]
\end{aligned}
$$

1.10 Parameter uncertainties and statistical range of predictions

To ensure the long-term serviceability (and in some cases safety) of structures sensitive to creep and shrinkage [6], the model parameters must be considered as statistical variables. The B4 and B4s formulae as presented so far give the mean values of $J\left(t, t^{\prime}\right)$ and $\epsilon_{s h, t o t a l}$. Uncertainty 
factors must be introduced on the primary model parameters to estimate the deviations from the mean.

In view of the separate and independent functional forms, the parameters $q_{1}, q_{2}, q_{3}, q_{4}, q_{5}, \tau_{s h}, \epsilon_{s h \infty}, \tau_{a u}$, and $\epsilon_{a u \infty}$ were selected to be replaced by the values:

$\psi_{1} q_{1}, \psi_{2} q_{2}, \psi_{2} q_{3}, \psi_{3} q_{4}, \psi_{4} q_{5}, \psi_{5} \tau_{s h}, \psi_{6} \epsilon_{s h}, \psi_{7} \tau_{a u}$,

and $\psi_{8} \epsilon_{a u \infty}$

in which the $\psi$ parameters capture the deviations from the model fitted to the full NU database of creep and shrinkage tests. According to statistical analysis, a lognormal distribution is recommended for all of them since it is found to match the observed variations best. As a result, the following 5 and $95 \%$ confidence limits should be imposed on the uncertainty factors:

For creep : $\psi_{1}[0.6,1.8], \psi_{2}[0.4,3.3], \psi_{3}[0.4,2.7]$,

$$
\psi_{4}[0.4,3.1]
$$

For shrinkage $: \psi_{5}[0.5,2.5], \psi_{6}[0.5,3.1], \psi_{7}[0.6,4.6]$,

$$
\psi_{8}[0.6,5.7]
$$

While the deviations from the mean parameter values listed here are quite large, it is important to note that they are nearly uncorrelated (correlation $<0.2$ between any two). Thus they likely do not act in full simultaneously.

The time functions associated with each of these parameters are a series of superimposed time functions with similar shapes. Because of similarity of the shapes, the selected parameters can be identified with a narrow scatter band only when matched to a limited subset of data one at a time, as described in [23]. When working with all the available test data, the intrinsic scatter is much too broad to deduce any functional form of the creep or shrinkage time functions or quantify the degree of model uncertainty; see Fig. 1 in [23].

An additional uncertainty stems from the fluctuations of environmental conditions. Extrinsic input parameters such as temperature, relative humidity, and compressive strength should be considered as random variables, too.

For nonstandard conditions of very high temperatures, very dry environments, or cyclic humidity and loading, additional complexities must be considered in the formulation to get an accurate prediction. For high temperatures beyond the range of what is listed as applicable to this model, only integration of the differential equations for creep rate can provide a good estimate. Explicit expressions for dealing with cyclic environments are provided in [26]. Such nonstandard conditions typically cause additional creep and shrinkage and, in that case, estimates should be made with a higher degree of uncertainty.

\subsection{Extrapolation of short-time tests and benefit of measuring weight loss during shrinkage}

The best way to reduce the uncertainty is to update the model parameters based on short-time tests of a given concrete. The updating is particularly effective and easy for creep, and even a 1-month test reduces the uncertainty greatly $[6,7]$. But, for shrinkage, the updating is more difficult due to the impossibility of determining the shrinkage halftime from shrinkage measurements of the usual short durations.

The uncertainty in extrapolating drying shrinkage can greatly be reduced if the weight loss is measured simultaneously with the shrinkage. The reason is that the halftimes of drying shrinkage and of weight loss are roughly the same, and, unlike the shrinkage halftime, the weight loss halftime can be calculated since the final water loss can be closely estimated. Unfortunately, although this method was proposed and demonstrated long ago (see Eqs. 1.30-1.34 and Fig. 1.4 in [7]), the database still contains only two such test data sets among hundreds. An alternative shrinkage extrapolation exploiting the diffusion size effect on halftime is discussed in [27].

\subsection{Cyclic creep and prestressing steel relaxation}

The cyclic creep of concrete under traffic loads, which has often been erroneously blamed for excessive deflections, is not part of model B4. According to a recent study [28], it has no appreciable effect on the bridge deflections (although it can produce, on top and bottom of bridge girders of small spans, significant tensile strains and cracking).

It must also be emphasized that a realistic structural creep analysis must include the incremental calculation of prestress loss in prestressing steel tendons, according to the evolution equation in which the tendon steel strains are coupled with the creep strains in concrete. Such analysis is demonstrated in $[1,2]$. 


\subsection{Concluding remarks and model justification}

A design based on the most realistic creep and shrinkage model is important for multi-decade durability and sustainability of structures. The problem has often been taken lightly because damages due to creep seldom occur in less than than 20-30 years. But whether a structure has the lifetime of 20 or 100 years makes a tremendous difference for the future of national economy. The theoretical and physical basis of models B3 and B4 have already been presented in previous works. The experimental justification and calibration, along with the method of optimizing the fit of the database and statistical comparison with other creep and shrinkage models, will be presented in the three papers that follow $[22,23]$.

Acknowledgments Generous financial support from the U.S. Department of Transportation, provided through Grant 20778 from the Infrastructure Technology Institute of Northwestern University, is gratefully appreciated. So is an additional support under U.S. National Science Foundation Grants CMMI-1129449 and CMMI1153494 to Northwestern University. Thanks are also due for additional financial support by the Austrian Federal Ministry of Economy, Family and Youth and the National Foundation for Research, Technology and Development and from the Austrian Science Fund (FWF) in the form of Erwin Schrödinger Scholarship J3619-N13. Valuable feedback on the final draft by Prof. V. Křístek is appreciated.

\section{References}

1. Bažant ZP, Yu Qiang, Li Guang-Hua (2012) Excessive long-time deflections of prestressed box girders: I. Recordspan bridge in Palau and other paradigms. ASCE J Struct Eng 138(6):676-686

2. Bažant ZP, Yu Qiang, Li Guang-Hua (2012) Excessive long-time deflections of collapsed prestressed box girders: II. Numerical analysis and lessons learned. ASCE J Struct Eng 138(6):687-696

3. Bažant ZP, Hubler MH, Yu Q (2011) Pervasiveness of excessive segmental bridge deflections: Wake-up call for creep. ACI Struct J 108(6):766-774

4. Müller HS, Hilsdorf HK (1990) "Evaluation of the timedependent behaviour of concrete: summary report on the work of the General Task Force Group No. 199." CEB (Comité euro-internationale du béton), Lausanne, p 201

5. Hubler MH, Wendner R, Bažant ZP (2014) "Comprehensive database for concrete creep and shrinkage: analysis and recommendations for testing and recording." ACI (in press)

6. Bažant ZP, Baweja S (1995) "Creep and shrinkage prediction model for analysis and design of concrete structures: Model B3." RILEM Recommend Mater Struct 28:357-367 (Errata, 29:126)

7. Bažant ZP, Baweja S (2000) "Creep and shrinkage prediction model for analysis and design of concrete structures: model
B3." Adam Neville symposium: creep and shrinkage-structural design effects, ACI SP-194. Al-Manaseer A (ed) Am. Concrete Institute, Farmington Hills, Michigan, pp 1-83

8. Bažant ZP, Prasannan S (1989) Solidification theory for concrete creep. I: formulation. J Eng Mech ASCE 115(8):1691-1703

9. Bažant ZP, Hauggaard AB, Baweja S, Ulm F-J (1997) Microprestress-solidification theory for concrete creep. I. Aging and drying effects. J Eng Mech ASCE 123(11):1188-1194

10. Committee RILEM TC-69 (1988) "State of the art in mathematical modeling of creep and shrinkage of concrete." In: Bažant ZP (ed) Mathematical modeling of creep and shrinkage of concrete, Wiley, New York, p 57-215

11. Jirásek M, Bažant ZP (2002) Inelastic analysis of structures. Wiley, New York

12. Yu Q, Bažant ZP, Wendner R (2012) Improved algorithm for efficient and realistic creep: analysis of large creepsensitive concrete structures. ACI Struct J 109(5):665-676

13. Bažant ZP (1972) Prediction of concrete creep effects using age-adjusted effective modulus method. Am Concr Inst J 69:212-217

14. ACI Committee 435 (2003) "Control of deflection in concrete structures." ACI 435R-95. Appendix B

15. Fédération Internationale du Béton (2010) Structural Concrete: Textbook on Behaviour, Design and Performance, vol 51. Int. du Béton, FIB-Féd

16. Granger L (1995) Comportement différé du béton dans les enceintes de centrales nucléaires: analyse et modélisation, Ph.D. thesis, ENPC, Research Report, Laboratoire Centrale des Ponts et Chaussées, Paris

17. Navrátil J (1998) "Updating of prediction of creep and shrinkage of concrete" (In Czech: "Upřesnění predikce dotvarování a smrštování betonu”), Stavební obzor 7 (2), pp 44-50

18. ACI Committee 209 (2008) Guide for modeling and calculating shrinkage and creep in hardened concrete ACI Report 209.2R-08, Farmington Hills

19. Bažant ZP, Panula L (1978) "Practical prediction of timedependent deformations of concrete." Materials and structures (RILEM, Paris) 11, pp 307-316, 317-328, 415-424

20. Wang J, Yan P, Yu H (2007) “Apparent activiation energy of concrete in early age determined by adiabatic test." J Wuhan Univ Tech Mater Sci 22(3), pp 537-541

21. Poole JL et al (2007) Methods for calculating activation energy for Portland cement. ACI Mater J 104(1):303-311

22. Hubler MH, Wendner R, Bažant ZP (2015) "Statistical justification of model B4 for drying and autogenous shrinkage of concrete and comparisons to other models." RILEM Mater Struct. doi:10.1617/s11527-014-0516-Z

23. Wendner R, Hubler MH, Bažant ZP (2014) Optimization method, choice of form and uncertainty quantification of model B4 using laboratory and multi-decade bridge databases. RILEM Mater Struct. doi:10.1617/s11527-0140515-0

24. Müller HS, Anders IB, Reiner R Vogel M (2013) "Concrete: treatment of types and properties in fib Model Code 2010", Structural Concrete 14(4):320-334

25. Nasser KW, Al-Manaseer A (1986) Creep of concrete containing fly ash and superplasticizer at different stress/ strength ratios. Am Concr Inst J 62:668-673

26. Bažant ZP, Kim J-K, Panula L (1992) Improved prediction model for time dependent deformations of concrete Part 5 cyclic load and cyclic humidity. Mater Struct 25:163-169 
27. Bažant ZP, Donmez A (2015) "Extrapolation of short-time drying shrinkage tests based on measured diffusion size effect: concept and reality." Mater Struct. doi:10.1617/ s11527-014-0507-0
28. Bažant ZP, Hubler MH (2014) "Theory of cyclic creep of concrete based on Paris law for fatigue growth of subcritical microcracks.” J Mech Phys Solids 63:187-200 